\title{
Clinicopathological spectrum of testicular lesions over a five-year period in a tertiary hospital
}

\author{
Sohaila Fatima ${ }^{1}$, Rabab Nasir Mohamed Badri², Wajih Ahmed Siddiqui ${ }^{3}$, Nihal Ibrahim Mirza ${ }^{4}$ \\ ${ }^{1}$ Dr. Sohaila Fatima, Department. of Pathology, King Khalid University, Abha, KSA ${ }^{2}$ Dr. Rabab Nasir Mohamed Badri, \\ Department. of Laboratory Medicine, Aseer Central Hospital, Abha, KSA ${ }^{3}$ Dr. Wajih Ahmed Siddiqui Hemato-Oncology \\ Department, Aseer Central Hospital, Abha, KSA ${ }^{4}$ Dr. Nihal Ibrahim Mirza, Department. of Laboratory Medicine, Aseer \\ Central Hospital, Abha, KSA
}

Corresponding Author: Dr. Sohaila Fatima, King Khalid University, Abha, KSA. E-mail: sohailafatima@gmail.com

\begin{abstract}
Objectives: To study the clinical pattern and histopathological features of testicular biopsies and orchiectomy specimens in patients presenting to a tertiary hospital. Methods: A 5 year retrospective study was conducted in histopathology section of Department of Laboratory Medicine, ACH from January 2014 to December 2018 on testicular tissue specimens (biopsies and orchiectomies). The histopathological diagnosis was made based on light microscopy followed by special stains and immunohistochemistry wherever indicated. Results: A total of 91 specimens were received in ACH during this 5 year period. The specimens comprised of cryptorchidism (16 cases), trauma (5 cases), vascular lesionstesticular torsion (17 cases), inflammatory lesions (11 cases), Sertoli cell only syndrome (2 cases), spermatogenic arrest ( 3 cases), atrophy ( 3 cases), obstructive causes leading to infertility ( 3 cases), cyst ( 2 cases), tumors ( 28 cases) and 1 was unremarkable .Inflammatory lesions were predominantly abscess (6 cases ), granulomatous orchitis (5 cases ).Tumors were classified into germ cell tumors -seminomas (10 cases), mixed germ cell tumors (9 cases), teratomas (3 cases), embryonal carcinoma ( 2 cases), spermatocytic tumors (3 cases), Leydig cell tumor ( 1 case). Conclusions: The present study revealed that testicular masses were predominantly neoplastic mostly malignant primarily seen in age group 21-30 years with seminomas constituting $35.7 \%$ of all tumors. Testicular torsion leading to ischemic necrosis were also seen in a large number of cases. Testicular biopsies might help in determining etiology of infertility which could be cryptorchidism, spermatogenic arrest, Sertoli cell only syndrome, atrophy and post testicular obstruction.
\end{abstract}

Keywords: Clinicopathological spectrum, Orchiectomy specimens, Testicular lesions

\section{Introduction}

The testicles (male gonads) are paired organs that lie within the scrotum suspended by the spermatic cord. Distinct pathological conditions affect the testes including congenital anomalies, inflammations, vascular disorders and tumors. Orchiectomies are performed for removal of testes in cases of tumors, trauma, torsion and undescended testes.

Testicular biopsy may be part of the diagnostic process of infertile men, but usually testicular histology does not explain the real cause of infertility. It merely confirms a disturbance of spermatogenesis in men with low sperm concentrations and elevated follicle-stimulating hormone. Testicular biopsy plays a distinctive role in the diagnosis of obstructive azoospermia azoospermia: in

Manuscript received: $29^{\text {th }}$ September 2019

Reviewed: $8^{\text {th }}$ October 2019

Author Corrected: $13^{\text {th }}$ October 2019

Accepted for Publication: $18^{\text {th }}$ October 2019 these men, surgical repair of the genital tract may be feasible and result in the presence of spermatozoa in the semen and spontaneous pregnancies. In most cases, however, a routine diagnostic testicular biopsy will not alter therapeutic options [1]. Testicular neoplasms comprise the most common solid malignancy affecting males between the ages of 15 and 35, although they represent only approximately 1 percent of all solid tumors in men [2] Testicular neoplasms can be divided into two major categories: germ cell tumors (GCT) and sex cord-stromal tumors (SC-ST). GCT are subdivided into seminomas and nonseminomatous tumors. Seminomas are commonest testicular malignant tumors seen worldwide [3]. Incidence rate of 5.7 and mortality rate of 0.3 per 100,000 persons was found during 20102014. Total number of new cases were found to be 12,371 and maximum percentage of new cases $50.3 \%$ were seen in age group 20-34 years. 


\section{Original Research Article}

Testicular cancer is the most common cancer in men with estimated 8850 new cases and estimated 410 deaths in 2017 [4]. The disease specific survival of GCTs in Europe is $97 \%$ at 1 year and $93 \%$ at 5 years, the highest survival rate for any malignant tumour in men [5]. Most GCT are aggressive cancers capable of rapid, wide dissemination although with current therapy most can be cured. SC-ST are generally benign [3]. The aim of present study is to analyze the pattern of testicular lesions in a tertiary center and to classify the tumors as per latest World Health Organisation (WHO) 2016.

\section{Material and Methods}

Setting- Aseer Central Hospital, Abha which is a tertiary center in southwest Kingdom of Saudi Arabia Duration- Five year period from January 2014 to December 2018

Type of study- Retrospective observational study Sampling methods and Sample size calculationTesticular biopsies and orchiectomy specimens received by histopathology section of Department of laboratory medicine during this period
Inclusion criteria-All testicular specimens

Exclusion criteria-Lesions involving testicular coverings are not included

Data collection procedure- This retrospective study consisted of 91 testicular biopsies and orchiectomy specimens with available histopathological data of patients from records of department of laboratory medicine during this 5 year period. The histopathological diagnosis was made based on light microscopy followed by special stains and immunohistochemistry wherever indicated.

Data analysis-The basic statistical analysis of cases and findings were done manually which has been represented by percentages

Ethical consideration \& permission- The data are collected from histopathological section of department of laboratory medicine. For this necessary permission are obtained from the concerned authorities. Identity of the patient and the treating doctor is not recorded.

\section{Results}

A total of 91 specimens were received in $\mathrm{ACH}$ during this 5 year period. The specimens comprised of cryptorchidism (16 cases), trauma (5 cases), vascular lesions-testicular torsion (17 cases), inflammatory lesions (11 cases), Sertoli cell only syndrome ( 2 cases), spermatogenic arrest ( 3 cases), atrophy ( 3 cases), obstructive causes leading to infertility ( 3 cases), cyst ( 2 cases), tumors ( 28 cases) and 1 was unremarkable. Inflammatory lesions were predominantly abscess ( 6 cases ), granulomatous orchitis (5 cases ). Tumors were classified into GCT-seminomas (10 cases), mixed germ cell tumors ( 9 cases), teratomas ( 3 cases), embryonal carcinoma ( 2 cases), spermatocytic tumors ( 3 cases), $S C$-ST -Leydig cell tumor (1 case). Right sided testicular involvement was noted in 17 cases whereas left sided in 11 cases. The age varied from 1 to 100 years with mean age of 30.6 years with predominant involvement of 21-30 years group (15 cases). Pure GCT were predominantly seminomas $(35.7 \%)$, teratomas $(10.7 \%)$ whereas in mixed tumors $(32.1 \%)$ embryonal carcinoma followed by teratoma and yolk sac tumor were the predominant components.

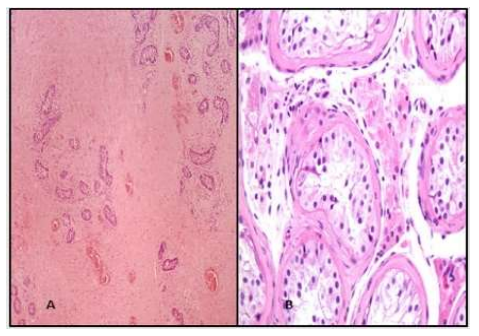

Fig.-1: A. Testicular Torsion B. Cryptorchidism (Hematoxylin and Eosin).

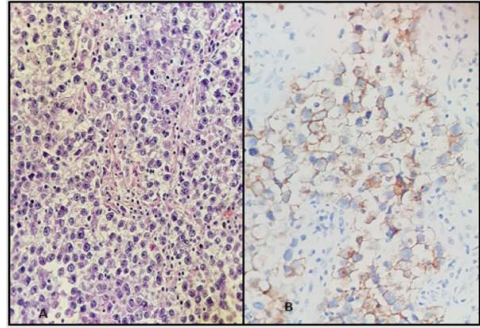

Fig. 2: A. Seminoma (Hematoxylin and Eosin) B. CD117 positivity in malignant cells of seminoma. 
Original Research Article

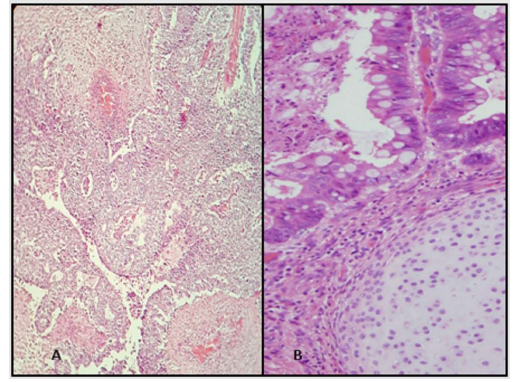

Fig. 3: A. Embryonal carcinoma B. Teratoma (Hematoxylin and Eosin).

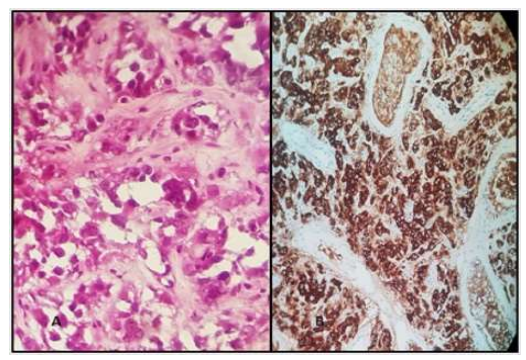

Fig. 4: A. Leydig cell tumour (Hematoxylin and Eosin) B. Inhibin positivity in tumour cells.

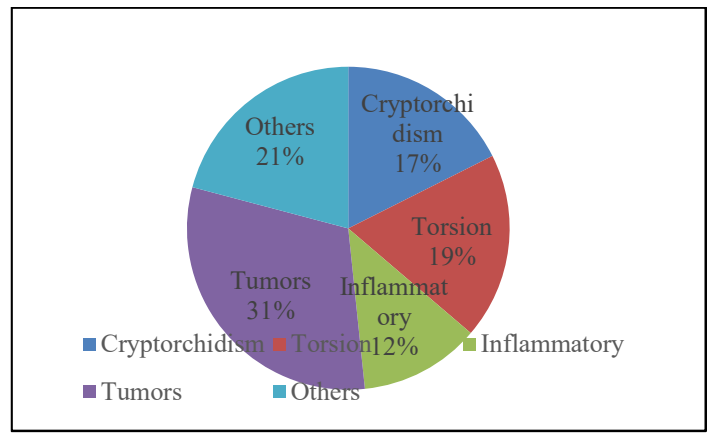

Figure 5: Testicular lesions.

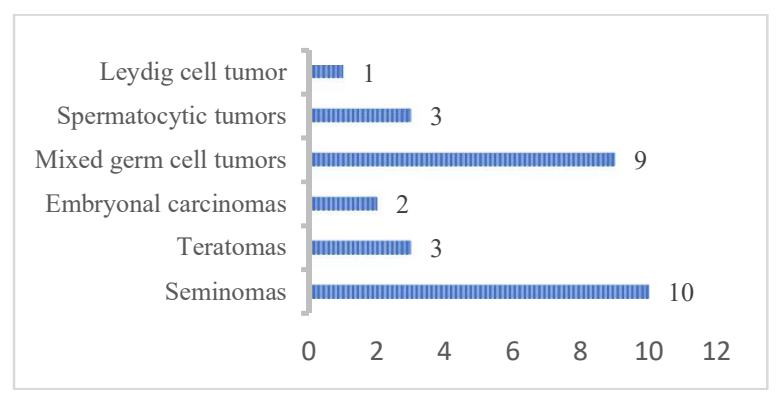

Figure 6: Distribution of tumors according to numbers.

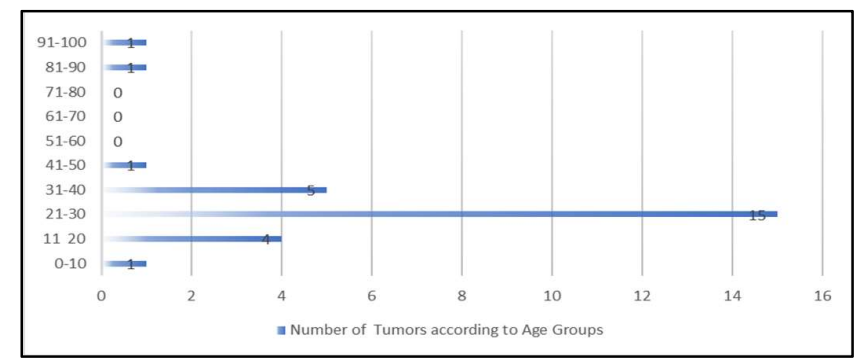

Figure 7: Distribution of tumors according to age groups. 


\section{Discussion}

Orchiectomies are performed for carcinoma of the testes, trauma or torsion of testis, undescended testis (cryptorchidism), certain cases of prostate cancer whose growth is testosterone dependent. Testicular biopsies can be performed for diagnostic and therapeutic reasons. The indications for a testicular biopsy are obstructive azoospermia for confirmation of the presence of normal spermatogenesis, testicular sperm extraction for sperm harvesting in men with nonobstructive azoospermia and diagnosis of testicular neoplasms [1].

Scoring of spermatogenesis is based on five main histological patterns of spermatogenesis: (i) absence of seminiferous tubules (tubular sclerosis); (ii) no germ cells within the seminiferous tubules (Sertoli cell-only syndrome) (iii) incomplete spermatogenesis, not beyond the spermatocyte stage (spermatogenic arrest) ; (iv) all germ cell stages present including spermatozoa, but there is a distinct decline in the number of germ cells (hypospermatogenesis); and (v) normal spermatogenesis [6].

In our centre the cases comprised of tumors (30.7\%), testicular torsion (19\%), cryptorchidism (17\%), inflammatory lesions (12\%), trauma (5.4\%) . Twisting of the spermatic cord typically leads to testicular 8partial failure of the intra-abdominal testes to descend into the scrotal sac and is associated with testicular dysfunction and an increased risk of testicular cancer (mostly GCT). It is found in approximately $1 \%$ of 1year-old boys. Inflammations are distinctly more common in the epididymis than in the testis [3].

Testicular cancer is a rare malignancy worldwide and among Saudis too. It is largely a disease of young- and middle-aged men, approximately $7 \%$ of cases occur in children. Testicular cancer accounts for around $1 \%$ of all cancer in males [7]. The incidence is highest in Europe and North America and lowest in Asia and Africa. The age-standardized incidence rate in Europe and North America is between 4 and 10/100,000, whereas in Asia and Africa is between 0.2 and $1 / 100,000[8,9]$. The incidence rate of testicular cancer was around 30.5 cases/year in the first decade (19942013), but a steadily significant increase in incidence rate in the second decade (2004-2013) was seen with a mean of 70 cases/year in KSA [7]. Similar patterns of increased incidence have been seen in neighboring Gulf Cooperation Council states [10] and other parts of world [11]. The incidence of malignancy is greater in cryptorchid organs with seminoma being the most common type [12]. As per KSA data $4.58 \%$ of the patients had tumors in undescended testis, most of which were seminomas [7]. In the present study just 1 case $(3.5 \%)$ of seminoma had association with cryptorchidism which goes with the above findings but much lower than other studies from KSA [13, 14]. 2\%$5 \%$ of testicular carcinoma patients harbour carcinoma in situ in their contralateral testis that will progress into an invasive GCT over time [1]. Contralateral testicular biopsy might be offered to high-risk patients i.e., patients with a testicular volume less than $12 \mathrm{ml}$, men with a history of cryptorchidism and in the case of ultrasonographic abnormalities according to the recommendations of the European Germ Cell Cancer Consensus Group [15].

Testicular tumors can be divided into five general categories: GCT arising from the germinal epithelium of the seminiferous tubules; SC-ST; mixed GCT-SCST; primary tumors not specific to the testis; and metastatic tumors [12]. According to latest world health organization (WHO) classification GCT are divided into categories based on their relationship with germ cell neoplasia in situ (GCNIS) previously termed intratubular germ cell neoplasia, unclassified (ITGCN) [16]. Majority (51\%) of all testicular cancers were found between 20-34 years in KSA [5]. In the present study predominant involvement of 21-30 years group was found going with the above study. Few studies on testicular tumors have been reported from different regions of KSA [ 13, 14, 17-19].

Seminomas make up $30 \%-40 \%$ of all testicular tumors [12]. Previously seminomas were classified into classic and spermatocytic types but as per latest WHO classification they constitute different categories and only classic seminomas are considered seminomas. In data from KSA seminomas constituted $40.7 \%$ of tumors (including spermatocytic tumors) In the present study 10 cases $(35.7 \%)$ were seminomas with mean age of 29.3 years. The tumor cells are uniform with abundant clear cytoplasm, sharply outlined cell membranes, and large centrally located nuclei with nucleoli. They are arranged in nests outlined by fibrous bands which are infiltrated by lymphocytes (the large majority of T-cell type), plasma cells, and histiocytes [20].

Under the current WHO criteria, testicular teratomas should be divided into prepubertal and post-pubertal subtypes, which generally correspond to the patient's age in relation to puberty. The present study had 1 case of prepubertal and 2 postpubertal teratoma cases.

Pathology Update: Tropical Journal of Pathology \& Microbiology Available online at: www.medresearch.in 787 | P a g e 
Embryonal carcinoma has a grossly more variegated appearance and heterogeneous architectural patterns. Two cases were in the present study. Spermatocytic tumors (ST) are included in GCT unrelated to GCNIS category and should be clearly separated from classic seminoma [13]. It comprises approximately $1 \%$ of testicular GCT and typically occurs in an older age group (mean 52-59 years) compared to seminoma [15]. The present study had 3 cases of ST with mean age being 73.3 years which was more than standard age. Mixed GCT are composed of more than one of the pure patterns. In most instances the prognosis is worsened by the presence of the more aggressive element [3]. Mixed tumors constituted 9 cases $(32.1 \%)$ with embryonal carcinoma followed by teratoma and yolk sac tumor being the main components. As per Saudi cancer registry, 2014 they constituted $24.2 \%$ [21] whereas data from USA showed 40\% [22].

Leydig cell tumors comprise between $1 \%$ and $3 \%$ of all testicular tumors. The present study had 1 case of this tumor $(3.5 \%)$ which was benign. Most Leydig cell tumors behave in a benign fashion, but about $5 \%$ show evidence of malignant behavior in the form of metastatic disease, particularly to lymph nodes, lung, and liver [15].

Limitation- This is a retrospective study where histopathological re-evaluation of testicular carcinomas was done in light of new WHO system. A further study is recommended involving large numbers of cases.

\section{Conclusion}

In the present study revealed that testicular masses were predominantly neoplastic mostly malignant primarily seen in age group 21-30 years with seminomas constituting $35.7 \%$ of all tumors. Testicular torsion leading to ischemic necrosis were also seen in a large number of cases. Testicular biopsies might help in determining etiology of infertility which could be cryptorchidism, spermatogenic arrest, Sertoli cell only syndrome, atrophy and post testicular obstruction.

\section{What this study adds to existing knowledge?}

This study enables us to know the relative frequency of testicular lesions in patients presenting to a tertiary hospital in southwest KSA, a region relatively unexplored in these terms. Testicular masses were predominantly neoplastic mostly malignant in the present study. Histopathology being mainstay of diagnosis contributes in accurate management of these patients.

\section{Original Research Article}

\section{Author's contribution}

Dr. Sohaila Fatima: Concepts, design, definition of intellectual content, literature search, clinical studies, data acquisition, data analysis, statistical analysis, manuscript preparation, manuscript editing, manuscript review.

Dr. Rabab Nasir Mohamed Badri: Concepts, definition of intellectual content, clinical studies, data acquisition, statistical analysis, manuscript preparation, manuscript editing, manuscript review.

Dr. Wajih Ahmed Siddiqui: Concepts, definition of intellectual content, literature search, clinical studies, data analysis, statistical analysis, manuscript preparation, manuscript editing, manuscript review.

Dr. Nihal Ibrahim Mirza: Concepts, Literature search, Clinical studies, Data acquisition, Manuscript preparation, Manuscript review

Funding: Nil; Conflict of Interest: None initiated Permission from IRB: Yes

\section{References}

1. Dohle GR, Elzanaty S, Van Casteren NJ. Testicular biopsy: clinical practice and interpretation. Asian J Androl. 2012;14(1):88. doi:10.1038/aja.2011.57

2. Siegel RL, Miller KD, Jemal A. Cancer statistics, 2019. CA Cancer J Clin. 2019;69(1):7-34. doi: 10.3322/caac.21551. Epub 2019 Jan 8.

3. Epstein JI. The lower urinary tract and male genital system. Robbins and Cotran Pathologic Basis of Diseases, $8^{\text {th }}$ ED. Saunders, 2005.

4. Howlader N, Noone AM, Krapcho M, Miller D, Brest A, Yu M, Ruhl J, Tatalovich Z, Mariotto A, Lewis DR, Chen HS, Feuer EJ, Cronin KA (eds). SEER Cancer Statistics Review, 1975-2016, National Cancer Institute. Bethesda, MD, https://seer.cancer.gov/csr /1975_2016/, based on November 2018 SEER data submission, posted to the SEER web site, April 2019.

5. Gori S, Porrozzi S, Roila F, Gatta G, De Giorgi U, Marangolo M. Germ cell tumours of the testis. Crit Rev Oncol/Hematol. 2005;53(2):141-164. doi: 10.1016/j. critrevonc.2004.05.006.

6. Nistal M, Paniagua R. Testicular biopsy. Contemporary interpretation. Urol Clin North Am. 1999;26(3):555-593. doi:https://doi.org/10.1016/S00940143(05)70200-7.

7. Abomelha M. Adult testicular cancer: Two decades of Saudi national data. Urol Ann. 2017;9(4):305-309. doi: 10.4103/UA.UA_11_17.

Pathology Update: Tropical Journal of Pathology \& Microbiology Available online at: www.medresearch.in 788 | P a g e 


\section{Original Research Article}

8. Hanna N, Timmerman R, Foster R, Roth B, Einhom L, Nichols C. Epidemiology of testicular cancer. In: Bast RC, Gansler TS, Holland JF,editors. Holland-Frei Cancer Medicine. $6^{\text {th }}$ ed. Hamilton, ON: BC Decker;2003.

9. Ekbom A, Akre O. Increasing incidence of testicular cancer-birth cohort effects. Apmis. 1998;106 (1-6):225-231. doi: https://doi.org/10.1111/j. 16990463. 1998.tb01340.x.

10. Cancer Incidence among Nationals of the GCC States 1998-2009, Gulf Center for Cancer Control and Prevention (GCCCP), King Faisal Specialist Hospital and Research Centre;2013. p. 26-31.

11. Znaor A, Lortet-Tieulent J, Jemal A, Bray F. International variations and trends in testicular cancer incidence and mortality. Eur Urol. 2014;65(6):10951106. doi: 10.1016/j.eururo.2013.11.004. Epub 2013 Nov 14

12. McKenney JK. Testis and testicular adnexa. In: Goldblum, JR; Lamps, LW; McKenney, JK; Myers, JL, editors. Rosai and Ackermans surgical pathology. $11^{\text {th }}$ ed. Mosby St. Louis, Missouri; 2017. p.1135-1174.

13. Bissada NK, el Senoussi M, Hanash KA, Hefty T, Morcos R. Testicular seminomas in Saudi Arabia: clinical characteristics, prognostic indicators, and recommendations for management. J Surg Oncol. 1986;33(2):136-139. doi: 10.1002/jso.2930330218.

14. el-Senoussi MA, Bissada NK, el-Akkad S, Bedikian AY, Morcos R, Bull C. Epidemiology and clinical characteristics of testicular tumors in Saudi Arabia: King Faisal Specialist Hospital and Research Centre experience. J Surg Oncol. 1987;35(1):39-41. doi: 10.1002/jso. 2930350109.
15. Schmoll HJ, Souchon R, Krege S, Albers P, Beyer $\mathrm{J}$, Kollmannsberger $\mathrm{C}$, et al. European consensus on diagnosis and treatment of germ cell cancer: a report of the European Germ Cell Cancer Consensus Group (EGCCCG). Ann Oncol. 2004;15(9):1377-1399. doi: 10.1093/annonc/mdh301.

16. Moch H, Cubilla AL, Humphrey PA, Reuter VE, Ulbright TM. The 2016 WHO Classification of Tumours of the Urinary System and Male Genital Organs-Part A: Renal, Penile, and Testicular Tumours. Eur Urol. 2016;70(1):93-105. doi: 10.1016/j.eururo. 2016.02.029. Epub 2016 Feb 28.

17. Rabadi S, Ayyat F, Milad M. Testicular cancer at Aramco Dhahran Health Center. Urol Ann. 2016;8 (Suppl 1):S76-S77.

18. Darwiche F, Gomha MA, Al-Mousa R, Al-Oraifi I, Jad A, Khan I, et al. Testicular tumors: King Fahad Specialist Hospital, Dammam experience. Urol Ann. 2016; 8 (Suppl 1):S76-S77.

19. Barayan G, Farsi H, Nassir A, Salawi R, Saada H. Testicular cancer at KFSH\&RC-Jeddah, Saudi Arabia: Importance of clinical features. Urol Ann 2016;8(1): S76-S77.

20. Cope NJ, McCullagh P, Sarsfield PT. Tumour responding accessory cells in testicular seminoma: an immunohistochemical study. Histopathology. 1999;34 (6):510-526. doi:10.1111/j.1365- 2559.1999. 00683.x

21. Saudi Cancer Registry, Cancer Incidence Report Saudi Arabia. 2014. Available at https ://nhic. gov. sa/ eServices/Documents/2014.pdf

22. Carver BS. Testicular cancer. In: Gomella LG, editor. The 5-Minute Urology Consult. $3^{\text {rd }}$ ed. Philadelphia: Wolters Kluwer; 2015. p. 486-511.

\section{How to cite this article?}

Sohaila Fatima, Rabab Nasir Mohamed Badri, Wajih Ahmed Siddiqui, Nihal Ibrahim Mirza, Clinicopathological spectrum of testicular lesions over a five-year period in a tertiary hospital. Trop J Path Micro 2019;5(10):784789.doi:10.17511/jopm.2019. i10.06. 